\title{
The Authors Reply: Discrepancy Between Quarterly Recall and Annual Recall of Falls: What is the Optimal Interval for Telephone Surveys?
}

First, we would like to present sincere gratitude for your interest in and appreciation of our work.

We agree with your opinion that there may be bias in asking the participants to recall falls over the last 3 months and also over the last year. However, that limitation had to be endured to compare the sum of quarterly recall and one annual recall over the period of the same year involving only telephone surveys. An interesting point to note is that we believed the participants who experienced falls earlier during the year would have higher discrepancy rates than those who experienced falls during the last quarter since memory decay develops over time." As seen in Table 2, the participants who fell only during the first quarter had higher recall discrepancy than the rest, although the statistical power could not be computed with significance. Of 19 participants who fell during the 4th quarter, 11 were new fallers, and, of these 11 fallers, $4(36.4 \%)$ showed recall discrepancy, which is lower than the average recall discrepancy of others. We analyzed the clinical characteristics between the discrepant and matching recall groups, but there was no statistically significant difference between the 2 groups, and we did not include the analysis in the publication.

The most accurate method of identifying falls would be continuous monitoring of participants, but that is neither practical nor possible with community-dwelling older adults.

\section{Chang Won Won}

Department of Family Medicine, College of Medicine, Kyung Hee University, Seoul, Korea

Corresponding Author: Chang Won Won, MD, PhD

Department of Family Medicine, Kyung Hee University Medical Center, 23 Kyunghee dae-ro, Dongdaemun-gu, Seoul 02447, Korea

Tel: +82-2-958-8691, Fax: +82-2-958-8699

E-mail: chunwon62@naver.com

Received: March 8, 2018

Revised: March 8, 2018

Accepted: March 10, 2018

The second best method would be to report or record any fall immediately using calendar, ${ }^{2)}$ diary, ${ }_{1}^{3)}$ postcard, ${ }_{1}^{4)}$ or direct phone call, as you mentioned. However, the purpose of our study was to provide a stepping stone for finding the optimal interval for telephone surveys during studies involving a large number of people such as the 2014 Survey of Living Conditions and Welfare Needs of Korean Older Persons, because most studies gather the data annually due to cost-benefit or administrative problems. ${ }^{5,6)}$

Therefore, the fundamental question you raised in the letter continues to be the same question we started asking, and we believe this question must be tackled with more studies targeting different intervals. Furthermore, this issue is not only of medical concern, but also studies focusing on the economic and political aspects of the issue should be conducted to establish the optimal interval for telephone surveys.

Conflicts of Interest Disclosures: The researcher claims no conflicts of interest.

\section{REFERENCES}

1. Jenkins P, Earle-Richardson G, Slingerland DT, May J. Time dependent memory decay. Am J Ind Med 2002;41:98-101.

2. Tromp AM, Pluijm SM, Smit JH, Deeg DJ, Bouter LM, Lips P. Fall-risk screening test: a prospective study on predictors for falls in community-dwelling elderly. J Clin Epidemiol 2001;54: 837-44.

3. Hill AM, Hoffmann T, Haines TP. Circumstances of falls and falls-related injuries in a cohort of older patients following hospital discharge. Clin Interv Aging 2013;8:765-74.

4. Dawson-Hughes B, Harris SS, Krall EA, Dallal GE. Effect of calcium and vitamin $\mathrm{D}$ supplementation on bone density in men and women 65 years of age or older. N Engl J Med 1997;337: 670-6.

5. Stull DE, Leidy NK, Parasuraman B, Chassany O. Optimal recall periods for patient-reported outcomes: challenges and potential solutions. Curr Med Res Opin 2009;25:929-42.

6. Jeong G, Oh Y, Kang E, Kim J, Sunwoo D, Oh M, et al. 2014 Survey of living conditions and welfare needs of Korean older persons. Sejong (Korea): Korea Institute for Health and Social Affairs; 2014 